\section{COVID-19 pandemic and management on hospital length of stay: A review}

\author{
Fatemeh Abdollahi, ${ }^{1}$ Seilan Ghanyan, ${ }^{1}$ \\ Farkhondeh Asadi ${ }^{2}$
}

${ }^{1}$ Department of Technology and Management, Shahid Beheshti University of Medical Science, Tehran; ${ }^{2}$ Health Information Technology and Management Department, Shahid Beheshti University of Medical Science, Tehran, Iran

\begin{abstract}
COVID-19 virus is a serious threat to public health everywhere on the planet. The World Health Organization (WHO) declared the disease epidemic in December 2019 because of its rapid prevalence around the world. The disease is transferred by inhalation or contact with contaminated droplets, and the incubation period varies from 2 to 14 days. COVID-19 has led to unprecedented pressures as demand for healthcare in hospitals and intensive care units around the world increases. As the epidemic intensifies, determining the resulting needs for health care resources (beds, staff, equipment) has become a priority for many countries. Predicting future demand requires estimating how long COVID-19 patients must have access to different levels of hospital care. The length of hospitalization for these patients is one of the management priorities. It is possible to pass through the crisis only with careful planning and comprehensive cooperation.
\end{abstract}

\section{Introduction}

In 2019, the 2019-nCoV or acute respiratory syndrome (SARS-CoV-2) spread from Wuhan, China, to other parts of the world. ${ }^{1}$ The virus was uncontrollable and caused the deaths of many people around the world. Preliminary data show that the elderly and those with weakened immune systems are more prone to the disease, while children are less likely to get sick. Preventive measures are the best way to control this disease. ${ }^{2}$ Risk factors of SARSCoV-2 activation are relevant to the immune system suppressor, such as aging, being a man, diseases such as diabetes, cardiovascular problems, weight gain, and preexisting viral diseases. Infectious viruses may remain hidden in the body, and they appear at the same time as other active viruses. SARS-CoV-2 may allow the activation of these sub-viruses. ${ }^{3,4}$

The epidemic COVID-19 makes proper management and isolation essential to prevent further outbreaks in the world..$^{5}$ Less current symptoms at COVID-19, such as nausea, vomiting, diarrhea, are transmitted by person-to-person. ${ }^{6}$ Patients with symptoms like fever, dry cough, and metabolic process distress should refer to the hospital. ${ }^{7}$ Also, people who have more severe symptoms of the disease should be hospitalized to continue the treatment. Hospital systems have been challenged by the influx of patients. ${ }^{8}$ Hospital care such as patient monitoring, sample testing, infection control in health centers, maintenance of necessary resources, pathways, beds, staff, and equipment required in the hospital, can affect the length of hospital stay. ${ }^{9}$ Many countries have failed despite having well-equipped sanitation systems and beds in hospitals. ${ }^{10}$ The increasing demand for hospital beds, as well as staff and related equipment, provides basic evidence indicating the need for careful decision-making and planning. LoS, long normal, and Weibull estimation models can be used to predict the number of beds needed by hospitalized patients. ${ }^{11}$ Obviously, taking such measures is reflected in the hospital admissions and Health Information Technology (HIT), supposed to be key restrictive parameters for hospitalized patients. ${ }^{12}$ The relative shortage of hospital beds and the high incidence of the disease, the increase in the risk of mortality, and the delay by physicians in the discharge of patients until full recovery, may make it difficult to identify the appropriate level of health care. ${ }^{13}$ The study aims to raise awareness of the efforts made by health policymakers and hospital managers to better predict the needs of hospitalized patients while protecting them during the COVID-19 epidemic. $^{14}$

\section{COVID-19 as a pandemic in hospitals}

The disease brought by coronavirus is of the most recent crises in human society, which spread worldwide and was declared as an epidemic by WHO on March, 11, 2020. In Italy, which had the highest number of patients after China, almost twothirds of all hospital beds were filled with COVID-19 patients whitin 10 days..$^{15}$ Thus, hospitals were placed at the forefront of the healthcare system and crisis response. ${ }^{16}$ Health managers and policymakers now control and manage the situation in a different context. Identifying the challenges
Correspondence: Fatemeh Abdollahi, Department of Technology and Management, Shahid Beheshti University of Medical Science, Tehran University of Medical Sciences, Tehran, Iran.

E-mail: f.abdollahii92@gmail.com

Acknowledgements: This study was supported by Mrs. Samira Hosseini from Tabriz University of Medical Sciences.

Conflict of interest: The authors declare no conflict of interest.

Key words: COVID-19; length of stay; quality health care; SARS-CoV-2; hospitalization.

Availability of data and materials: All data generated or analyzed during this study are included in this published article.

Ethics approval and consent to participate: The Ethics Committee of Shahid Beheshti University of Medical Science, Tehran approved this study (IR.SBMU.VCR REC.1398.395). The study is conformed with the Helsinki Declaration of 1964, as revised in 2013, concerning human and animal rights. All patients participating in this study signed a written informed consent form for participating in this study.

Informed consent: Written informed consent was obtained from a legally authorized representative(s) for anonymized patient information to be published in this article.

Received for publication: 23 August 2021

Revision received: 22 September 2021

Accepted for publication: 4 October 2021.

This work is licensed under a Creative Commons Attribution 4.0 License (by-nc 4.0).

OCopyright: the Author(s), 2021

Licensee PAGEPress, Italy

Healthcare in Low-resource Settings 2021; 9:10057 doi:10.4081/hls.2021.10057

in hospitals, along with the implementation of effective strategies in the face of biological crises, can play an important role in crisis management planning. ${ }^{17}$.It is also possible to extend these programs to other countries. ${ }^{18,19}$ At the start of the COVID-19 pandemic, hospital managers could use the total capacity of hospital beds, ${ }^{18}$ trying to discharge patients with lower priority and concentrate on more critical conditions. ${ }^{20}$ Then, separate clinical centers were allocated to COVID-19 suspected patients to manage hospital patient flow. $^{21}$ Restrictions were also imposed on visits for the wards designated to these patients. ${ }^{22}$ In addition to the restrictions and hospitalization of many patients, there were 
several efforts to use the simplest accessible resources and facilities in the best way. ${ }^{23}$ Accordingly, crisis management specialists coordinated closely with alternative hospitals. ${ }^{24}$

\section{Hospital support measures asso- ciated with the COVID-19}

In the early phase of the pandemic, information on the disease was still evolving; thus, case definitions and hospital pointers were most often modified. ${ }^{25}$ Hospitals became scenes of super-spreading events throughout the disease and MERS epidemic. ${ }^{26}$ Outpatients and emergency groups were supposed to be at a higher risk. ${ }^{27}$ All facilities were mobilized to establish elaborate strategies aimed at safe testing and effective quarantine of suspects. ${ }^{28}$ Otherwise, uncertainties of those on the forefront and the increasing number of patients would turn such locations into hospital-related epidemics. ${ }^{29}$ The allocation of a unit to assess medical services by an associate in nurse staffing requirements may act as a security barrier to the construction. ${ }^{30}$ Sorting can be a clinical strategy to deal with patients who have acute metabolism illnesses. ${ }^{31}$ For example, as in the case of associate in nurse staffing, initial testing, treating the disease, and managing different cases can be performed with voluntary home quarantine. ${ }^{32}$ Then, if it does not respond, COVID-19 visits and examinations can be performed at intervals of 5 to 9 days. $^{33}$ The use of telemedicine or telecommunications is usually supposed to reduce the need to travel to outpatients. ${ }^{34}$ Hospitals got to establish potential programs for general wards and treatment units. ${ }^{35}$ Caring for patients with COVID-19 requires an associate degree and large rooms and areas to quarantine mobile contaminants, which means exceeding the available capacities. ${ }^{36}$

The adjustment of air conditioning systems is also a useful solution to deal with the crisis Worldwide. ${ }^{37}$ Heating, Ventilation, and Air Conditioning (HVAC), along with waste management and handling, have been at the center of attention in public departments to manage patients with COVID-19. ${ }^{38}$ Pharmacies and private offices face particular challenges due to the lack of capabilities for quarantine and testing. ${ }^{39}$ An efficient flow of patient testing and referrals is very important, and the cooperation of competent public health professionals with society is required to support healthcare foundations effectively. ${ }^{40}$

\section{Communications and manage- ment of patients, visitors, and staff}

At the early phase of virus prevalence, hospital guidelines often underwent revisions. ${ }^{41}$ Now, strict measures of isolation and protection are the main priorities to deal with this disease. ${ }^{42}$ Nurses are provided with online training on how to protect against and prevent coronavirus infection in their hospitals to increase staff awareness and communication ${ }^{43}$ (Figure 1). Coordination between all employees is also necessary. ${ }^{44} \mathrm{All}$ staff should report their respiratory symptoms and body temperature before and after exposure to patients with COVID-19 while avoiding entrance into unnecessary wards. ${ }^{45}$ The staff must carry out all programs according to the instructions given by the hospital manager. ${ }^{46}$

\section{Patient management}

Managers focused on discharging patients who had better conditions through international agencies or taking their admission to completely different hospitals or clinics so that they could take advantage of the hospital's full capacity. ${ }^{47}$ The closure of the operation rooms and rejection of elective patients aimed at prevent patient flow to the hospitals. ${ }^{48}$ Also, COVID-19 suspected patients were assigned distinct clinical centers providing visits and administrative procedures. ${ }^{49}$ A follow-up center was also established for those patients who received care, but their administrative unit did not institutionalize the reception process. ${ }^{50}$ Patients admitted at home had access to routine contacts and residential care nursing groups when required. ${ }^{51}$ the Red Crescent Society and other volunteers helped in the establishment of patient centers. ${ }^{52}$ Visits of the wards in which COVID-19 patients were hospitalized were also restricted or prohibited (Figure 2). ${ }^{53}$

Patient position: Must be manufactured to isolate patients with doubtful or established COVID-19.54

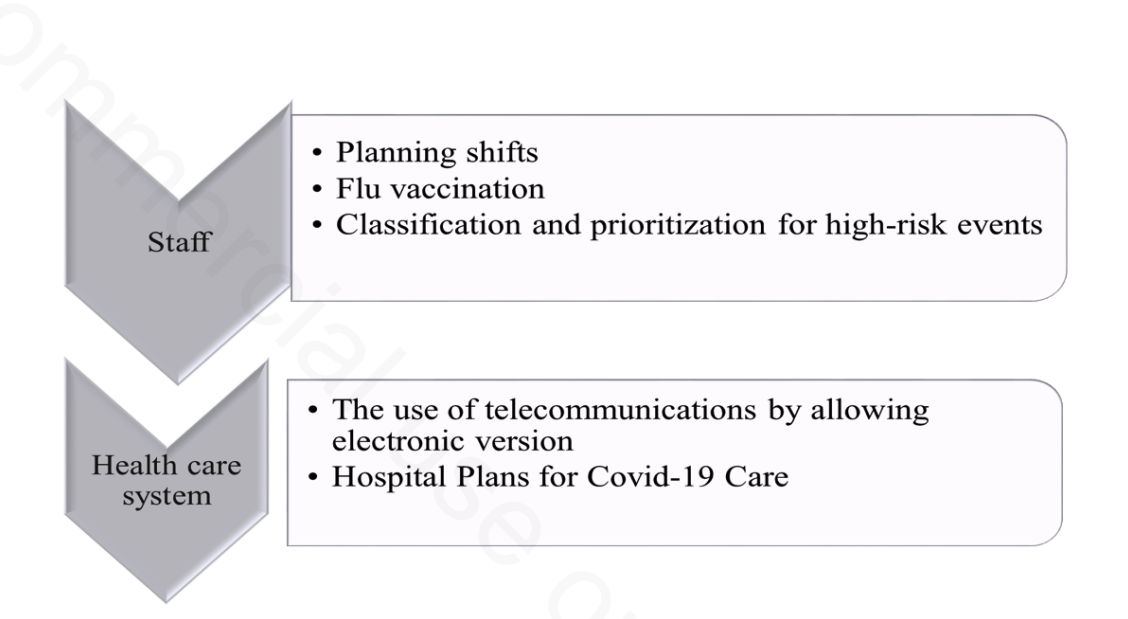

Figure 1. Proposals for hospital.

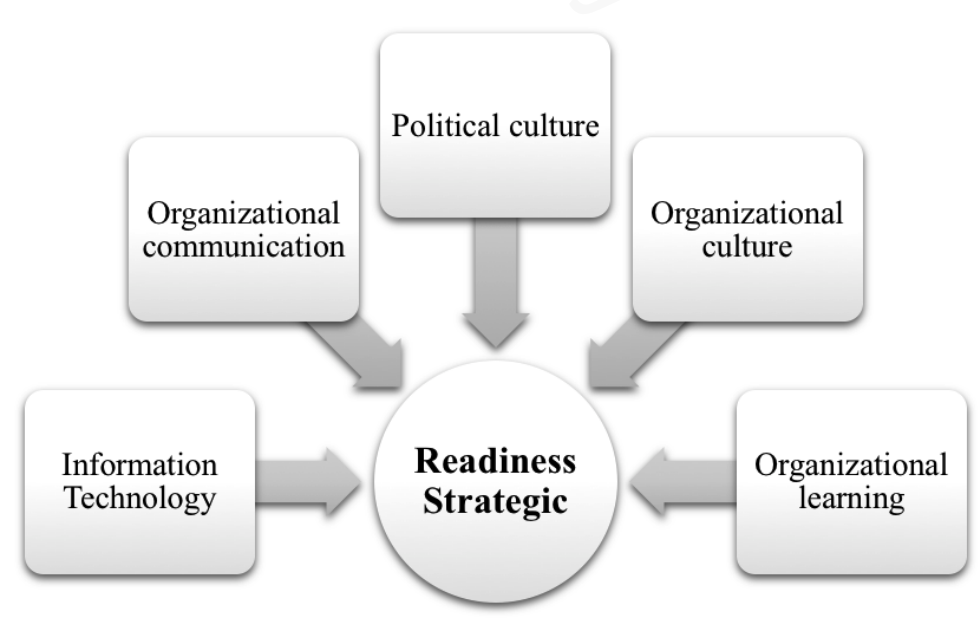

Figure 2. Theoretical topics of research in the hospital. 
Patient education: Napkins should be prepared and patiently instructed to cover the nose and mouth. ${ }^{55}$

\section{Management of items and facili- ties}

Considering the constraints, together with higher chances of hospitalization within the next phases of the pandemic, the attempt was made to use the available resources and equipment effectively. ${ }^{56}$ Accordingly, in addition to the effective use of the resources and provisions, the consultants in crisis management coordinated with alternative hospitals to arrange donations and fund facilities such as personal protection kits, masks, gloves, and disinfectants. ${ }^{57}$ Also, because of the lack of resources and facilities to treat infected individuals, specialized hospitals such as medicine or medical specialty centers need exclusion from the cycle of the fight against the pandemic. ${ }^{58}$ As the patient variety increases, coordination with alternative establishments is necessary to create field hospitals. ${ }^{59}$

\section{Conclusions}

Nowadays, the diffusion of up to date on the latest information on COVID-19 is an important method that can into the performance of self-care guidance. Control of this disease requires society's involvement and presentation information about COVID-19 to the society has a key role in managing critical conditions ${ }^{60}$ The prevalence of the novel virus has challenged the infrastructure of many countries in the world, affecting the lives of all humans. ${ }^{61}$ Moreover, we need to consider the behavioral variations of COVID-19, and its longterm effects in the human body. ${ }^{62}$ Emergency and disaster readiness is an important and global issue. ${ }^{63}$ Most hospitals are unable to maintain their normal operations for a week due to a lack of disasterrelated resources. ${ }^{64}$ However, it is possible to overcome the epidemic with the necessary preparations and the coordination and cooperation of all hospital departments, including staff, doctors, and nurses. ${ }^{65}$ In this review study, the hospital system monitored staff performance to detect significant changes and take appropriate measures for patients admitted to COVID-19 wards. ${ }^{66}$ To change the patients' length of stay in the hospital, it is important to use hospital management techniques and coordinate with health centers in the community. ${ }^{67}$ Adherence to protocols, health and care guidelines, and social distancing between people can decrease virus infection cases. ${ }^{68}$ Compliance with the principles of health and self-care make it possible to prevent acute cases of the disease and hospitalization. ${ }^{69}$

\section{References}

1. Rinaldi F, Trink A, Pinto D. Efficacy of Postbiotics in a PRP-Like Cosmetic Product for the Treatment of Alopecia Area Celsi: A Randomized DoubleBlinded Parallel-Group Study. Dermatol Ther (Heidelb) 2020;10:483493.

2. Pfefferbaum B, North CS. Mental Health and the Covid-19 Pandemic. N Engl J Med 2020;383:510-2.

3. Mehraeen E, Seyed Alinaghi SA, Nowroozi A, Dadras O, Alilou S, Shobeiri P, Behnezhad F, Karimi A. A systematic review of ECG findings in patients with COVID-19. Indian Heart J 2020;72:500-7.

4. SeyedAlinaghi S, Oliaei S, Kianzad S, et al. Reinfection risk of novel coronavirus (COVID-19): A systematic review of current evidence. World $\mathrm{J}$ Virol 2020;9:79-90.

5. Mehraeen E, Karimi A, Barzegary A, et al. Predictors of mortality in patients with COVID-19-a systematic review. Eur J Integr Med 2020;40:101226.

6. Mehraeen E, Behnezhad F, Salehi MA, et al. Olfactory and gustatory dysfunctions due to the coronavirus disease (COVID-19): a review of current evidence. Eur Arch Otorhinolaryngol 2021;278:307-12.

7. Israelsen SB, Kristiansen KT, Hindsberger B, et al. Characteristics of patients with COVID-19 pneumonia at Hvidovre Hospital, March-April 2020. Danish Med J 2020;67.

8. Borobia AM, Carcas AJ, Arnalich F, et al. A cohort of patients with COVID-19 in a major teaching hospital in Europe. J Clin Med 2020;9:1733.

9. Zhao Y, Wei L, Liu B, Du D. Management of transplant patients outside hospital during COVID-19 epidemic: A Chinese experience. Transpl Infect Dis 2020;22:e13327.

10. Rees EM, Nightingale ES, Jafari Y, et al. COVID-19 length of hospital stay: a systematic review and data synthesis. BMC Med 2020;18:270.

11. Vekaria B, Overton C, Wiśniowski A, et al. Hospital length of stay for COVID19 patients: Data-driven methods for forward planning. BMC Infect Dis 2021;21:1-15.
12. Vallecillo G, Anguera M, Martin N, Robles MJ. Effectiveness of an Acute Care for Elders unit at a long-term care facility for frail older patients with COVID-19. Geriatr Nurs 2021;42:5447.

13. Eimer J, Vesterbacka J, Svensson AK, et al. Tocilizumab shortens time on mechanical ventilation and length of hospital stay in patients with severe COVID-19: a retrospective cohort study. J Intern Med 2021;289:434-6.

14. Wang Z, Ji JS, Liu Y, et al. Survival analysis of hospital length of stay of novel coronavirus (COVID-19) pneumonia patients in Sichuan, China. medRxiv 2020; https://doi.org/10.1101/2020.04.07.200 57299.

15. Trehan A, Jain R, Bansal D. Oncology care in a lower middle-income country during the COVID-19 pandemic. Pediatr Blood Cancer. 2020 Aug;67(8):e28438.

16. Wu J, Mamas M, Rashid M, et al. Patient response, treatments, and mortality for acute myocardial infarction during the COVID-19 pandemic. Eur Heart J Qual Care Clin Outcomes 2021;7:238-46.

17. Tay KH, Ooi CC, Mahmood MIB, et al. Reconfiguring the radiology leadership team for crisis management during the COVID-19 pandemic in a large tertiary hospital in Singapore. Eur Radiol 2021;31:468-74.

18. Xiang YT, Zhao YJ, Liu ZH, et al. The COVID-19 outbreak and psychiatric hospitals in China: managing challenges through mental health service reform. Int J Biol Sci 2020;16:1741-4.

19. NeJhaddadgar N, Ziapour A, Zakkipour $\mathrm{G}$, et al. Effectiveness of telephonebased screening and triage during COVID-19 outbreak in the promoted primary healthcare system: a case study in Ardabil province, Iran. J Public Health (Berl.) 2020; https://doi.org/ 10.1007/s10389-020-01407-8

20. Shao Y, Shao Y, Fei JM. Psychiatry hospital management facing COVID-19: From medical staff to patients. Brain Behav Immun 2020;88:947.

21. Sullivan EH, Gibson LE, Berra L, et al. In-hospital airway management of COVID-19 patients. Crit Care 2020;24:292.

22. Gagliano A, Villani PG, Co' FM, et al. COVID-19 Epidemic in the Middle Province of Northern Italy: Impact, Logistics, and Strategy in the First Line Hospital. Disaster Med Public Health Prep 2020;14:372-6.

23. Millard H, Wilson C, Fortunati F, Li L. 
COVID-19 psychiatric patients: Impact of variability in testing on length of hospital stay and disposition back to congregate care settings. Psychiatry Res 2020;292:113324.

24. Rajan N, Joshi GP. COVID-19: Role of Ambulatory Surgery Facilities in This Global Pandemic. Anesth Analg 2020;131:31-6.

25. Hao F, Tam W, Hu X, Tet al. A quantitative and qualitative study on the neuropsychiatric sequelae of acutely ill COVID-19 inpatients in isolation facilities. Transl Psychiatry 2020;10:355.

26. Peeri NC, Shrestha N, Rahman MS, et al. The SARS, MERS and novel coronavirus (COVID-19) epidemics, the newest and biggest global health threats: what lessons have we learned? Int J Epidemiol 2020;49:717-26.

27. Zhao J, Li H, Kung D, et al. Impact of the COVID-19 Epidemic on Stroke Care and Potential Solutions. Stroke 2020;51:1996-2001.

28. Liu Y, Wang $\mathrm{H}$, Chen $J$, et al. Emergency management of nursing human resources and supplies to respond to coronavirus disease 2019 epidemic. Int J Nurs Sci 2020;7:135-8.

29. Yu H, Sun X, Solvang WD, Zhao X. Reverse Logistics Network Design for Effective Management of Medical Waste in Epidemic Outbreaks: Insights from the Coronavirus Disease 2019 (COVID-19) Outbreak in Wuhan (China). Int $\mathrm{J}$ Environ Res Public Health 2020;17:1770.

30. Basu S. Non-communicable disease management in vulnerable patients during Covid-19. Indian $\mathrm{J}$ Med Ethics 2020; V:103-5.

31. Peiffer-Smadja N, Lucet JC, Bendjelloul G, et al. Challenges and issues about organizing a hospital to respond to the COVID-19 outbreak: experience from a French reference centre. Clin Microbiol Infect 2020;26:669-72.

32. Chew NWS, Lee GKH, Tan BYQ, et al. A multinational, multicentre study on the psychological outcomes and associated physical symptoms amongst healthcare workers during COVID-19 outbreak. Brain Behav Immun 2020;88:559-565.

33. Zhang J, Litvinova M, Wang W, et al. Evolving epidemiology and transmission dynamics of coronavirus disease 2019 outside Hubei province, China: a descriptive and modelling study. Lancet Infect Dis 2020;20:793-802.

34. Giacomelli A, Ridolfo AL, Milazzo L, et al. 30-day mortality in patients hospitalized with COVID-19 during the first wave of the Italian epidemic: A prospective cohort study. Pharmacol Res 2020;158:104931.

35. Song Z, Hu Y, Zheng S, et al. Hospital pharmacists' pharmaceutical care for hospitalized patients with COVID-19: Recommendations and guidance from clinical experience. Res Social Adm Pharm 2021;17:2027-31.

36. Aguwa UT, Aguwa CJ, Repka M, et al.Teleophthalmology in the era of COVID-19: characteristics of early adopters at a large academic institution. Telemed e-Health 2020;27:0372.

37. Cheng Y, Wei W, Zhong Y, Zhang L. The empowering role of hospitable telemedicine experience in reducing isolation and anxiety: evidence from the COVID-19 pandemic. Internat $\mathrm{J}$ Contem Hospitality Manag 2021;33:851-72.

38. Berger G, Horowitz NA, ShachorMeyouhas Y, et al. Hospital solution for COVID-19 isolation facility. Am J Disaster Med 2021;16:35-41.

39. Goff DA, Ashiru-Oredope D, Cairns $\mathrm{KA}$, et al. Global contributions of pharmacists during the COVID-19 pandemic. J Am Coll Clin Pharm 2020:10.1002/jac5.1329.

40. Greenhalgh T, Knight M, A'Court C, et al. Management of post-acute covid-19 in primary care. BMJ 2020;370:m3026.

41. Hoernke K, Djellouli N, Andrews L, et al. Frontline healthcare workers' experiences with personal protective equipment during the COVID-19 pandemic in the UK: a rapid qualitative appraisal. BMJ Open 2021;11:e046199.

42. Xu C, Jin J, Song J, et al. Application of refined management in prevention and control of the coronavirus disease 2019 epidemic in non-isolated areas of a general hospital. Int J Nurs Sci 2020;7:1437.

43. Alharthy A, Faqihi F, Mhawish H, et al. Configuring a hospital in the COVID19 era by integrating crisis management logistics. Infect Control Hosp Epidemiol 2021;42:911-3.

44. Grange ES, Neil EJ, Stoffel M, et al. Responding to COVID-19: The UW Medicine Information Technology Services Experience. Appl Clin Inform 2020;11:265-75.

45. Htun HL, Lim DW, Kyaw WM, et al. Responding to the COVID-19 Outbreak in Singapore: Staff Protection and Staff Temperature and Sickness Surveillance Systems. Clin Infect Dis 2020;71:194752.

46. Adams JG, Walls RM. Supporting the Health Care Workforce During the COVID-19 Global Epidemic. JAMA
2020;323:1439-40.

47. Jing ZC, Zhu HD, Yan XW, et al. Recommendations from the Peking Union Medical College Hospital for the management of acute myocardial infarction during the COVID-19 outbreak. Eur Heart J 2020;41:1791-4.

48. Janbabai G, Razavi S, Dabbagh A. How to manage perioperative patient flow during COVID-19 pandemic: a narrative review. J Cell Molecular Anesth 2020;5:47-56.

49. Lee I, Wang C, Lin M, et al. Effective strategies to prevent coronavirus disease-2019 (COVID-19) outbreak in hospital. J Hospital Infect 2020;105:102.

50. Fond G, Pauly V, Leone $\mathrm{M}$, et al. Disparities in Intensive Care Unit Admission and Mortality Among Patients With Schizophrenia and COVID-19: A National Cohort Study. Schizophr Bull 2021;47:624-34.

51. Abuhammad, S, Manar, A, Mukattash, T. The perception of nurses towards their roles during the COVID-19 pandemic. Int J Clin Pract 2021;75:e13919.

52. Abed Alah M, Ali K, Abdeen S, et al. The psychological impact of COVID19 on health care workers working in a unique environment under the umbrella of Qatar Red Crescent Society. Heliyon 2021;7:e07236.

53. Chang CM, Tan TW, Ho TC, et al. COVID-19: Taiwan's epidemiological characteristics and public and hospital responses. PeerJ 2020;8:e9360.

54. Krishnamurthy S. The future of business education: A commentary in the shadow of the Covid-19 pandemic. J Bus Res 2020;117:1-5.

55. Tabatabai S. COVID-19 impact and virtual medical education. J Adv Med Educ Prof 2020;8:140-3.

56. Eftekhar Ardebili M, Naserbakht M, Bernstein C, Alazmani-Noodeh F, Hakimi H, Ranjbar H. Healthcare providers experience of working during the COVID-19 pandemic: A qualitative study. Am J Infect Control 2021;49:547-54.

57. Kliger AS, Silberzweig J. Mitigating Risk of COVID-19 in Dialysis Facilities. Clin J Am Soc Nephrol 2020;15:707-9.

58. Mohammadi F, Farjam M, Gholampour $\mathrm{Y}$, et al. Health Professionals' Perception of Psychological Safety in Patients with Coronavirus (COVID-19). Risk Manag Healthc Policy 2020;13:785-94.

59. Reeves JJ, Hollandsworth HM, Torriani FJ, et al. Rapid response to COVID-19: health informatics support for outbreak 
management in an academic health system. J Am Med Inform Assoc 2020;27:853-9.

60. Mehraeen E, Hayati B, Saeidi S, et al. Self-Care Instructions for People Not Requiring Hospitalization for Coronavirus Disease 2019 (COVID19), Arch Clin Infect Dis 2020;15:e102978.

61. Yang P, Wang X. COVID-19: a new challenge for human beings. Cell Mol Immunol 2020;17:555-7.

62. SeyedAlinaghi S, Afsahi AM, MohsseniPour $M$, et al. Late Complications of COVID-19; a Systematic Review of Current Evidence. Arch Acad Emerg Med 2021;9:e14.

63. Matias T, Dominski FH, Marks DF. Human needs in COVID-19 isolation. SAGE Publications Sage UK: London, England, 2020.

64. Huang L, Lin G, Tang L, et al. Special attention to nurses' protection during the COVID-19 epidemic. Crit Care 2020;24:120.

65. Humam AM, Loh TC, Foo HL, et al. Dietary Supplementation of Postbiotics Mitigates Adverse Impacts of Heat Stress on Antioxidant Enzyme Activity, Total Antioxidant, Lipid Peroxidation, Physiological Stress Indicators, Lipid Profile and Meat Quality in Broilers. Animals (Basel) 2020;10:982.
66. Bambi S, Iozzo P, Lucchini A. New Issues in Nursing Management During the COVID-19 Pandemic in Italy. Am J Crit Care 2020;29:e92-e93.

67. Brindle ME, Gawande A. Managing COVID-19 in Surgical Systems. Ann Surg 2020;272:e1-e2.

68. Chen Q, Liang M, Li Y, et al. Mental health care for medical staff in China during the COVID-19 outbreak. Lancet Psychiatry 2020;7:e15-e16.

69. Mauffrey C, Trompeter A. Lead the way or leave the way: leading a Department of Orthopedics through the COVID-19 pandemic. Eur J Orthop Surg Traumatol 2020;30:555-7. 